\title{
Longitudinal, population-based study of self reported alcohol habits, high levels of sickness absence, and disability pensions
}

\author{
Marianne Upmark, Jette Möller, Anders Romelsjö
}

\begin{abstract}
Study objective-To analyse the relation between self reported hazardous drinking on the one hand and high sickness absence and/or disability pensions in both sexes on the other hand.

Design-The study is based on data from a health survey, Stockholm Health of the Population Study, conducted in 1984. The mailed questionnaire covered alcohol consumption. Three different measures of alcohol habits were used: usual alcohol consumption, consumption during the previous week, and answers to the four CAGE questions on problem drinking. Information from the health survey and data from a subsequent health examination were related to information from the National Swedish Social Insurance Board for the year 1984 and the years 1986 to 1991 concerning sick leave and disability pensioning.
\end{abstract}

Setting-Four primary health care districts in Stockholm County.

Participants-The study group included persons who were aged 20 to 52 years in 1984, who answered the questionnaire (by mail or by telephone), and who participated in the health examination. The study group comprised 985 women and 870 men fulfilling the criteria for inclusion out of 6217 subjects aged 18 years and over randomly drawn.

Main results-In both sexes, a consistent pattern of increased sickness absence was seen for high consumers and for those with indications of problem drinking. In most comparisons, a clearly increased relative risk, although not always statistically significant, for an average of at least 60 sick days per year or for a disability pension during follow up was found. In multivariate analysis, controlling for age, socioeconomic group, smoking habits, and self reported health, a small reduction in the relative risks was found, suggesting that these factors could explain only a small part of the relative risks. The risks for abstainers were higher than for low and moderate consumers.

Conclusions-The effects of alcohol on subsequent high levels of sickness absence five to seven years after baseline as well as on the occurrence of disability pensions suggested that there is an effect on working incapacity independent of baseline health status, smoking, and socioeconomic group. (F Epidemiol Community Health 1999;53:223-229)
The risk of sickness absences and disability pensions is influenced by several factors. Most studies on sickness absence have been focused on individual aspects, ${ }^{1}$ while a greater part of studies on disability pensions have been carried out on a societal level. On the individual level, among the most acknowledged factors influencing short or long absences, as well as disability pensions, are age, ${ }^{2-5} \mathrm{sex},{ }^{45}$ occupation and work related factors, ${ }^{4-8}$ and socioeconomic status. ${ }^{4-9}$ Among lifestyle factors, much interest has been focused on alcohol consumption. Intuitively, hazardous alcohol consumption and problem drinking influence the working capacity of a person because of psychiatric or physical sequalae of the alcohol use as well as because of social and psychological stress. There is evidence of a positive relation between high/risky alcohol consumption and sickness absence in general, measured as registered total number of sick days in both men and women. ${ }^{10-15}$ High alcohol consumption is also linked to disability pensioning (early retirement because of sickness or impairment). ${ }^{16-20}$ One limitation of some of these studies is that they have a cross sectional design limiting the possibility of causal analysis. ${ }^{10}{ }^{11} 16$ Other limitations of some studies with a longitudinal design are that they are not based on the general population, ${ }^{10} 1116$ that they are based on men only, ${ }^{15-20}$ or based on number of spells only. ${ }^{14}$ With access to information on self reported alcohol habits among the general population and exact, prospective data on sickness absence compensated by the social insurance, we could overcome some of these methodological problems.

The objective of this study was to analyse the relation between different indicators of self reported alcohol habits on the one hand and high levels of sickness absence/disability pensions in both sexes on the other hand during a follow up period of several years.

\section{Methods}

THE 1984 STOCKHOLM HEALTH OF THE POPULATION STUDY

The 1984-85 Stockholm Health of the Population Study (HPS) was used as baseline material and included both a questionnaire and a health examination. The questionnaire survey was carried out in the spring of 1984, and the health examination started a few months later and went on for about six months. The study was carried out in four of the 42 primary health care districts in Stockholm County. A random sample of 6217 subjects aged 18 and over was 
drawn from these areas. The main objective of the study was to broaden the scope for health care planning. ${ }^{21}$

A postal questionnaire was used to elicit responses on social conditions, diseases and impairment, use of outpatient health care, use of medical drugs, behavioural risks, physical activity, dietary habits, working conditions, social networks, social support, opinions on local primary health care, and alcohol consumption. Where possible, a telephone interview was conducted with those not replying to the questionnaire. In addition to the questionnaire, questions on alcohol habits were included in a health examination conducted some months later by local district nurses.

SUDY POPULATION

Because of our specific objectives, we included only those who were between 20 and 52 years of age in 1984. At that time (up until October 1991), anyone aged 60 or above may well have been granted an early retirement because of shortage of work. Early retirement for medical reasons was also easier to obtain for those 60 or older. Furthermore, the study includes only people who were financially qualified to receive sickness benefits from the social insurance office; no sick days were registered for people without this qualification.

To obtain a population that could be followed up for the entire period of seven years, and that could be said to be largely fit for work from the outset of the study, the following categories were excluded: those who died during follow up, disability pensioners in 1984, and those claiming 90 or more days of sickness allowance during 1984

The analyses were done for those who both answered the questionnaire (by mail or by telephone) and who participated in the health examination. After our exclusions, the study population consisted of 985 women and 870 men.

To assess how well the results could be generalised, additional analyses were done on separate participation subgroups.

INFORMATION ON SICK BENEFITS AND DISABILITY PENSIONING

For the years studied (1984-1991), all spells qualifying for sickness benefits (see below) were compensated by the social insurance office. Information concerning sickness absenteeism, disability pensions, and income qualifications for sickness benefits was obtained from the National Swedish Social Insurance Board, with the aid of the Swedish personal identification number, during 1994. Data for 1984 were obtained at the end of the survey in 1984. As information on sickness benefits is stored for only 10 years and as considerable changes were made in the sickness insurance system in 1992, the follow up data concern 1986 up until 1992. Our main interest was the influence of alcohol habits on very high sickness absence, irrespective of the distribution of absences or of the kind of compensation for loss of income from the social insurance system. Therefore, we thought it most meaningful to concentrate on the total number of disabled days (sick days) per person during a certain period. In addition, there is evidence that measuring the total days of sickness absence discriminates more consistently between high and light/moderate consumers of alcohol. ${ }^{10-13}$

Absence during part of the day was converted to parts of a whole day.

Sickness spells lasting more than seven days have to be certified by a physician. There was no upper limit for the duration of sickness allowance. All Swedish inhabitants with a minimum annual income of 6000 Swedish $\mathrm{Kr}$ are included in the insurance for sickness allowance from the age of 16 years.

Disability pension, as laid down by Swedish law, may be granted to a person between 16 and 65 years of age whose working capacity is judged to be permanently diminished because of illness or other physical or mental impairment. A temporary disability pension is granted, however, if a person's working capacity is judged to be reduced for a considerable time, but not permanently; such a pension is generally reviewed every year. There are no income criteria for getting a disability pension. In practice, it is unusual for a person with a temporary disability pension to return to work.

Persons who became disability pensioners during follow up were considered to have 365 sick days per year from the year when the disability pension was granted (or 180 days per year for half a disability pension).

The terms "sickness absence," "sick days," and "sickness allowance" are used interchangeably in this paper to mean absence from work reported to, and compensated by, the social insurance office as sickness allowance or occupational benefits. In addition, in this context, days compensated for by disability pensions or temporary disability pensions are included in the concept of sickness absence. In some analyses, we also handled disability pensioning specifically. The term "disability pension" also includes temporary disability pensions.

High sickness absenteeism was defined as an average number of at least 60 sick days per year during follow up.

\section{MEASURES OF ALCOHOL CONSUMPTION AND OTHER INDICATORS OF HAZARDOUS DRINKING Alcohol consumption}

Usual alcohol consumption was obtained from the postal questionnaire and from the telephone interview. Questions with fixed reply alternatives concerned the usual consumption of liquor, fortified wine, table wine, strong beer, and ordinary beer, and one further question enquired about occasions of high alcohol intake. Alcohol consumption during the past week was obtained from the questions asked during the health examination. If the participants had drunk alcohol during the previous week, they were asked about their consumption of each alcoholic beverage between Monday and Thursday and between Friday and Sunday. Consumption was converted to grams of $100 \%$ ethanol (100 g of alcohol correspond to approximately $30 \mathrm{cl}$ of spirits, $120 \mathrm{cl}$ of table wine, or $220 \mathrm{cl}$ of strong beer). The cut off 
Table 1 Mean number of days with sick allowance in 1984 and the mean number of days with sick allowancelyear during follow up from 1986 to 1991. Persons with more than 90 days of sick leave and persons who were disability pensioners in 1984 are excluded (1809 men and 1737 women are included)

\begin{tabular}{|c|c|c|c|c|}
\hline & \multicolumn{2}{|l|}{ Men } & \multicolumn{2}{|l|}{ Women } \\
\hline & 84 & $86-91$ & 84 & $86-91$ \\
\hline $\begin{array}{l}\text { Participants in both the questionnaire/telephone interview } \\
\text { and the health examination } 52.8 \%\end{array}$ & $\begin{array}{l}10.3 \\
\mathrm{n}=879\end{array}$ & 18.2 & $\begin{array}{l}13.4 \\
n=992\end{array}$ & 25.2 \\
\hline Participation only in the questionnaire survey $18.6 \%$ & $\begin{array}{l}9.4 \\
\mathrm{n}=350\end{array}$ & 19.7 & $\begin{array}{l}13.7 \\
\mathrm{n}=310\end{array}$ & 25.7 \\
\hline Participation only in the telephone interview $6.6 \%$ & $\begin{array}{l}12.8 \\
\mathrm{n}=132\end{array}$ & 26.6 & $\begin{array}{l}20.5 \\
\mathrm{n}=103\end{array}$ & 39.9 \\
\hline Participation only in the health examination $5.5 \%$ & $\begin{array}{l}13.1 \\
\mathrm{n}=87\end{array}$ & 26.3 & $\begin{array}{l}13.4 \\
n=108\end{array}$ & 39.6 \\
\hline No participation at all $16.5 \%$ & $\begin{array}{l}12.5 \\
\mathrm{n}=361\end{array}$ & - & $\begin{array}{l}15.5 \\
\mathrm{n}=224\end{array}$ & - \\
\hline
\end{tabular}

point for high alcohol consumption was set at $35 \mathrm{~g}$ per day for men and $25 \mathrm{~g}$ for women, consistent with recent recommendations. ${ }^{22}{ }^{23}$ Low consumption was defined as anything below $10 \mathrm{~g}$ for men per day and $7 \mathrm{~g}$ for women. Moderate consumption was defined as anything between low and high consumption.

\section{$C A G E$}

The four CAGE questions were included in the health examination interview. ${ }^{24}$ A positive answer to two or more of these was taken to indicate problem drinking.

DATA ANALYSIS

All analyses were stratified for sex. For most analyses, the average number of sick days in 1984 and/or the average number of sick days per calendar year during follow up from 1986 to 1991 was used. We used the mean as the average number of sick days as it is the prevalent measure of sick leave. As the distribution of sick days was skewed, we also present the results as the median in the descriptive analysis (see table 2).

Bivariate analyses were made using $2 \times 2$ contingency tables in which the relative risk was estimated with $95 \%$ confidence intervals. The multivariate analyses were then made by logistic regression. The models we used controlled for potentially confounding variables, such as age, smoking, socioeconomic group, and self rated health. Values for these variables were obtained from the postal questionnaire in 1984. The results are presented as relative risks (RR) with $95 \%$ confidence intervals.

\section{Results}

NUMBER OF SICK DAYS AMONG DIFFERENT PARTICIPATION GROUPS IN THE 1984 STOCKHOLM HEALTH OF THE POPULATION STUDY (HPS) The mean number of sick days listed in 1984 for those who participated in both the questionnaire/telephone interview and the health examination was 10.3 days for men and 13.4 days for women. The corresponding figures for those fulfilling our inclusion criteria but not actually participating in the study were 12.5 and 15.5 for men and women, respectively. There was little difference in the number of sick days taken by people answering the questionnaire, irrespective of whether they participated in the health examination. For those who participated only in the telephone interview or in the health examination, sickness absence during follow up was considerably higher for both men and women (see table 1).

NUMBER OF SICK DAYS RELATED TO THE DIFFERENT INDICATORS OF ALCOHOL CONSUMPTION

Reported alcohol consumption

Among all groups of participants, the average sick absenteeism per year during follow up was approximately doubled. The relation of alcohol consumption to sickness absence appears to be J shaped. Men, however, who reported at the health examination that they had abstained from drinking alcohol during the previous week had higher sickness absence both at baseline and during follow up than did men who were high consumers during the same period (see table 2).

According to the questionnaire, men with high consumption took an average of 28.5 sick days during follow up, whereas women with high consumption averaged 30.6. Low consuming men had 14.2 and low consuming women 22.2 sick days. According to answers reported at the health examination (consumption previous week) high consuming men had 20.8 and high consuming women 35.5 sick days. The corresponding figures for low consumers were 12.3 and 21.6 for men and women, respectively (see table 2 ).

\section{CAGE QUESTIONS}

Both men and women who answered positively to two or more of the CAGE questions had higher sickness absenteeism in 1984 than did those with one or no positive answer. During follow up there were pronounced differences in the median number of days with sickness allowances. There was a large increase in sickness absence in men and in women $(n=6)$ with three or four positive answers (see table 2).

RISK OF HIGH LEVELS OF SICKNESS ABSENCE/DISABILITY PENSION

Higher age, daily smoking, low socioeconomic group, and self rated rather bad-very bad health were consistently all predictors of high sickness absence/disability pension in women. In men no such consistent risk pattern (with statistically significant increased relative risks) was found (see table 3).

The relative risks were increased for almost all of the various indicators of hazardous 
Table 2 Mean and median number of days with sick allowance in 1984 and the average number of days with sick allowance/year during follow up from 1986 to 1991 related to three different alcohol indicators. Persons with more than 90 days of sick leave and persons who were disability pensioners in 1984 are excluded ( 870 men and 985 women are included)

\begin{tabular}{|c|c|c|c|c|c|c|c|c|c|c|}
\hline \multirow[b]{2}{*}{ Alcohol indicator } & \multicolumn{5}{|l|}{ Men } & \multicolumn{5}{|l|}{ Women } \\
\hline & $\begin{array}{l}84 \\
\text { Median }\end{array}$ & Mean & $\begin{array}{l}\text { 86-91 } \\
\text { Median }\end{array}$ & Mean & & $\begin{array}{l}84 \\
\text { Median }\end{array}$ & Mean & $\begin{array}{l}\text { 86-91 } \\
\text { Median }\end{array}$ & Mean & \\
\hline \multicolumn{11}{|c|}{ Usual alcohol consumption/day in questionnaire } \\
\hline Abstainers & 4.0 & 11.6 & 7.8 & 20.2 & $\mathrm{n}=156$ & 5.0 & 14.2 & 12.8 & 29.6 & $\mathrm{n}=290$ \\
\hline Low consumption* ${ }^{\star}$ & 3.0 & 7.9 & 4.8 & 14.2 & $\mathrm{n}=257$ & 5.0 & 12.3 & 11.9 & 22.2 & $\mathrm{n}=312$ \\
\hline $\begin{array}{l}\text { Moderate } \\
\text { consumption }\end{array}$ & 3.0 & 10.1 & 7.3 & 16.6 & $\mathrm{n}=386$ & 6.0 & 13.1 & 11.8 & 23.5 & $\mathrm{n}=345$ \\
\hline High consumption ${ }^{\star}$ & 5.0 & 15.8 & 10.3 & 28.5 & $\mathrm{n}=69$ & 9.0 & 15.5 & 14.8 & 30.6 & $\mathrm{n}=33$ \\
\hline \multicolumn{11}{|c|}{ Alcohol consumption/day (previous week) at health examination } \\
\hline Abstainers & 5.0 & 12.7 & 9.9 & 23.1 & $\mathrm{n}=260$ & 6.0 & 15.4 & 13.3 & 28.5 & $\mathrm{n}=440$ \\
\hline Low consumption ${ }^{\star}$ & 2.0 & 8.4 & 5.5 & 12.3 & $\mathrm{n}=293$ & 5.0 & 11.3 & 12.5 & 21.6 & $\mathrm{n}=307$ \\
\hline $\begin{array}{l}\text { Moderate } \\
\text { consumption }\end{array}$ & 3.0 & 9.9 & 6.7 & 16.8 & $\mathrm{n}=213$ & 4.0 & 10.9 & 9.3 & 20.2 & $\mathrm{n}=178$ \\
\hline High consumption ${ }^{\star}$ & 3.0 & 10.1 & 6.7 & 20.8 & $\mathrm{n}=96$ & 10.0 & 17.1 & 14.8 & 35.5 & $\mathrm{n}=48$ \\
\hline \multicolumn{11}{|c|}{ Positive answers on CAGE } \\
\hline $0-1$ & 3.0 & 8.8 & 2.3 & 16.1 & $\mathrm{n}=738$ & 5.0 & 12.8 & 11.8 & 24.0 & $\mathrm{n}=876$ \\
\hline 2 & 6.0 & 14.0 & 7.8 & 14.5 & $\mathrm{n}=63$ & 8.5 & 16.4 & 14.4 & 24.2 & $\mathrm{n}=40$ \\
\hline $3-4$ & 26.0 & 26.8 & 25.2 & 42.3 & $\mathrm{n}=32$ & 12.5 & 15.3 & 37.8 & 48.4 & $\mathrm{n}=6$ \\
\hline
\end{tabular}

$\star$ Definitions in grams of $100 \%$ alcohol/day: low consumption: men, $\leqslant 10$; women, $\leqslant 7$; moderate consumption: men, $\geqslant 10$ and $\leqslant 35$; women: $\geqslant 7$ and $\leqslant 25$; high consumption: men, $\geqslant 35$; women, $\geqslant 25$.

drinking, but were often not statistically significant. There were, in general, small differences between the size of the relative risks in bivariate and in multivariate analyses when adjusting for age, smoking habits, self rated health, and socioeconomic group (see table 4).

Among people who reported high alcohol consumption in the questionnaire, an almost fourfold increase in crude relative risks for men and more than doubled relative risks for women with an average of 60 or more sick days per year was found. In multivariate analysis, we found that the risks were reduced and were not statistically significant for women. In men with high consumption, an almost sixfold increase in risk for receiving a disability pension was found in the bivariate analysis, and a sevenfold increase was found in the multivariate analysis. For women, the corresponding increased risks, although not significant, were almost fourfold in the bivariate analysis and almost threefold in the multivariate analysis (see table 4).

High consumption (previous week) reported at the health examination was, significantly, associated with a 2.5-fold increase in risk for men and with a more than threefold increase in risk for women of suffering an average of at least 60 sick days per year. In multivariate analysis, these increases in risk were almost unchanged for women, while they decreased moderately for men. Women with a high consumption rate had a more than sixfold significant increase in risk of receiving a disability pension in the bivariate analysis, while no increased risk for receiving a disability pension was found among men with a high consumption rate. Among men with a moderate consumption rate, a potential for increased risk of high levels of sick leave and of receiving a disability pension was noted (see table 4).

Giving three or four positive answers to the CAGE questions was associated with high relative risks in both sexes; however, this was not significant in the multivariate analysis (see table 4).

For abstainers in general, we noted increased relative risks, although sometimes not statistically significant, of having high sickness absence and of receiving a disability pensions (see table 4).

In separate bivariate analyses on partial participants, either on all those people who had answered the questionnaire or on all those who had participated at the health examination, we found that the relative risks were similar to the risks for those participating in both the questionnaire and the health examination. This indicates that the results also are valid for the rest of the participants.

Table 3 Relative risks among men and women for high levels of sickness absence and disability pensioning at the end of follow up according to age, smoking, self rated health and socioeconomic group at baseline. Bivariate relative risks with $95 \%$ confidence intervals. Persons with more than 90 sick days and persons who were disability pensioners in 1984 are excluded (870 men and 985 women are included)

\begin{tabular}{|c|c|c|c|c|}
\hline \multirow[b]{2}{*}{ Variables } & \multicolumn{2}{|l|}{ Men } & \multicolumn{2}{|l|}{ Women } \\
\hline & $\begin{array}{l}\geqslant 60 \text { days/year } R R \\
(95 \% C I)\end{array}$ & $\begin{array}{l}\text { Disability pension } R R \\
(95 \% \text { CI })\end{array}$ & $\begin{array}{l}\geqslant 60 \text { days } / \text { year } R R \\
(95 \% C I)\end{array}$ & $\begin{array}{l}\text { Disability pension RR } \\
(95 \% \mathrm{CI})\end{array}$ \\
\hline \multicolumn{5}{|l|}{ Age } \\
\hline $20-35$ & 1.00 & 1.00 & 1.00 & 1.00 \\
\hline $36-52$ & $1.39(0.84,2.28)$ & $3.40(0.94,12.26)$ & $1.65(1.12,2.44)$ & $6.44(1.91,21.72)$ \\
\hline \multicolumn{5}{|l|}{ Daily smoking } \\
\hline No & 1.00 & 1.00 & 1.00 & 1.00 \\
\hline Yes & $1.74(1.07,2.85)$ & $0.92(0.29,2.95)$ & $1.91(1.30,2.83)$ & $1.85(0.77,4.41)$ \\
\hline \multicolumn{5}{|l|}{ Self rated health } \\
\hline Very good/neither good nor bad & 1.00 & 1.00 & 1.00 & 1.00 \\
\hline Rather bad/very bad & $1.17(0.30,4.51)$ & $2.77(0.38,20.49)$ & $3.44(1.81,6.54)$ & $10.05(3.68,27.43)$ \\
\hline \multicolumn{5}{|l|}{ Socioeconomic group } \\
\hline Non-manual employees, lower level & 1.00 & 1.00 & 1.00 & 1.00 \\
\hline Manual workers & $1.24(0.67,2.30)$ & $0.89(0.23,3.40)$ & $2.94(1.71,5.07)$ & $3.62(1.06,12.38)$ \\
\hline Non-manual employees, medium and higher level & $0.18(0.06,0.54)$ & $0.35(0.06,2.09)$ & $1.16(0.56,2.30)$ & $1.09(0.22,5.34)$ \\
\hline
\end{tabular}


Table 4 Relative risks among men and women for high levels of sickness absence and disability pensioning at the end of follow up according to three different indicators of hazardous drinking of alcohol. Bivariate and multivariatet relative risks with 95\% confidence intervals. Persons with more than 90 sick days and persons who were disability pensioners in 1984 are excluded (870 men and 985 women are included)

\begin{tabular}{|c|c|c|c|c|}
\hline \multirow{2}{*}{$\begin{array}{l}\text { RR univ }(95 \% \text { CI) } \\
\text { RR multi }(95 \% \text { CI })\end{array}$} & \multicolumn{2}{|l|}{ Men } & \multicolumn{2}{|l|}{ Women } \\
\hline & $\geqslant 60$ days/year & Disability pension & $\geqslant 60$ days/year & Disability pension \\
\hline \multicolumn{5}{|l|}{ Questionnaire } \\
\hline \multicolumn{5}{|l|}{ Usual consumption } \\
\hline \multirow[t]{2}{*}{ Abstainers } & $2.2(1.1,4.4)$ & $4.1(0.9,18.4)$ & $1.5(0.9,2.4)$ & $1.9(0.7,5.6)$ \\
\hline & $1.8(0.9,3.5)$ & $2.3(0.4,14.0)$ & $1.2(0.7,2.1)$ & $1.5(0.4,5.3)$ \\
\hline \multirow[t]{2}{*}{ Low consumption ${ }^{\star}$} & 1.0 & 1.0 & 1.0 & 1.0 \\
\hline & 1.0 & 1.0 & 1.0 & 1.0 \\
\hline \multirow[t]{2}{*}{ Moderate consumption ${ }^{\star}$} & $1.1(0.6,2.2)$ & $1.3(0.2,7.2)$ & $1.1(0.7,1.9)$ & $1.3(0.4,3.9)$ \\
\hline & $1.0(0.5,1.9)$ & $1.3(0.2,7.1)$ & $1.0(0.6,1.8)$ & $1.1(0.3,4.2)$ \\
\hline \multirow{2}{*}{ High consumption ${ }^{\star}$} & $3.7(1.8,7.6)$ & $5.6(1.2,27.0)$ & $2.3(1.0,5.2)$ & $3.9(0.8,7.1)$ \\
\hline & $2.9(1.4,5.4)$ & $6.8(1.1,40.5)$ & $1.8(0.7,4.5)$ & $2.8(0.4,8.5)$ \\
\hline \multicolumn{5}{|l|}{ Health examination } \\
\hline \multicolumn{5}{|l|}{ Consumption previous week } \\
\hline \multirow[t]{2}{*}{ Abstainers } & $3.0(1.6,5.6)$ & $2.3(0.6,8.6)$ & $1.6(1.0,2.5)$ & $3.0(0.9,9.9)$ \\
\hline & $2.5(1.3,4.4)$ & $1.6(0.4,7.2)$ & $1.3(0.8,2.2)$ & $2.0(0.5,7.4)$ \\
\hline \multirow{2}{*}{ Low consumption ${ }^{\star}$} & 1.0 & 1.0 & 1.0 & 1.0 \\
\hline & 1.0 & 1.0 & 1.0 & 1.0 \\
\hline \multirow[t]{2}{*}{ Moderate consumption ${ }^{\star}$} & $1.4(0.6,3.1)$ & $1.8(0.4,7.9)$ & $0.9(0.5,1.9)$ & $1.7(0.4,8.3)$ \\
\hline & $1.4(0.6,3.0)$ & $2.0(0.4,8.9)$ & $0.8(0.4,1.8)$ & $0.6(0.1,6.1)$ \\
\hline \multirow[t]{2}{*}{ High consumption ${ }^{\star}$} & $2.5(1.1,5.7)$ & $1.0(0.1,9.7)$ & $3.2(1.7,6.1)$ & $6.4(1.6,25.5)$ \\
\hline & $2.0(0.8,4.3)$ & $1.0(0.1,9.6)$ & $3.2(1.5,6.5)$ & $5.1(0.9,28.4)$ \\
\hline \multicolumn{5}{|l|}{ CAGE } \\
\hline \multirow[t]{2}{*}{$0-1$ positive answers } & 1.0 & 1.0 & 1.0 & 1.0 \\
\hline & 1.0 & 1.0 & 1.0 & 1.0 \\
\hline \multirow[t]{2}{*}{2 positive answers } & $0.3(0.0,1.6)$ & - & $1.1(0.4,2.9)$ & - \\
\hline & $0.2(0.0,1.6)$ & & $1.1(0.4,3.0)$ & \\
\hline \multirow[t]{2}{*}{ 3-4 positive answers } & $3.7(1.8,7.5)$ & $3.8(1.0,15.2)$ & $3.7(1.0,12.7)$ & - \\
\hline & $2.0(0.8,4.3)$ & $2.3(0.3,18.8)$ & $3.4(0.6,12.9)$ & \\
\hline
\end{tabular}

$\star$ Definitions in grams of $100 \%$ alcohol/day as in table 2 . $†$ Model adjusted for age, socioeconomic group, smoking habits, and self rated health.

\section{Discussion}

MAIN FINDINGS ON ALCOHOL CONSUMPTION AND SICKNESS ALLOWANCE

In this group of young to middle aged men and women, which from the baseline of the study excluded disability pensioners and persons with extremely high sickness absence, there was, in both sexes, a consistent pattern of increased sickness absence for high consumers and for those with indications of problem drinking. In most comparisons, a clearly increased relative risk, although not always statistically significant, for having an average of at least 60 sick days per year or for receiving a disability pension during follow up was found. In the multivariate analysis, controlling for age, socioeconomic group, smoking habits, and self rated health, it was found that these factors could explain only a small part of the relative risks found in the bivariate analysis. The higher rates of high levels of sickness absence in high consumers/problem drinkers may therefore be causal.

In addition, among moderate consumers, a tendency toward increased sickness absence and very high sickness absence/disability pension was found, compared with levels found in low consumers. As in some other studies, ${ }^{12} 141920$ risks for abstainers were found to be increased over those for low and moderate consumers. Presumably, causes other than potentially beneficial effects of alcohol are responsible for this difference. The abstainers probably constitute a heterogeneous group, differing in other aspects from low and moderate consumers. ${ }^{25}$ In addition, subgroups of non-consumers abstain because of earlier high consumption or because of poor health. Recovered alcoholics are known to have greater absenteeism than controls do. ${ }^{26}$
CHANGES IN RULES AND REGULATIONS DURING THE FOLLOW UP PERIOD

During follow up the annual sick leave rate in the whole of Sweden was increased from 18.8 days per sick leave insured in 1984 to 25.3 days per insured in 1988 and 22.5 days in $1991 .^{27}$ The period coincided with some important improvements in the Swedish sickness insurance system. Thus, in 1987, the qualifying day was taken away. Most insured persons, suffered no income loss because of sickness because many of those employed received financial top up from their employers. The follow up also coincides with a period of high employment rates and low unemployment rates. In 1990, $81.7 \%$ of the women and $86.0 \%$ of the men between the ages of 16 and 64 were members of the labour force; the unemployment was $3.1 \%$ in 1984 and less than $2 \%$ during the follow up period..$^{28}$ In March 1991 and in 1993, these rules were changed in a restrictive way. The sick leave rates were strongly reduced. At the same time there were dramatic changes in the labour market. In less than a year the high employment rates were followed by the highest unemployment rates in Sweden since the postwar period. The results of this study presumably are influenced by these great changes. But it is not possible to assess in which direction the relative risks are influenced. These great fluctuations in compensated sickness absence also merits interest as an illustration of the effect of structural factors on sick leave.

Besides the overall increase in sick leave during follow up, the exclusions made, and the aging of the study population ${ }^{2-5}$ presumably contributes to the great overall increase in sick days during follow up. 
ACCURACY OF THE VARIABLES

Underreporting of alcohol habits is common. The reliability of the alcohol consumption measures are more throughly described in an earlier report on the HPS study. ${ }^{29}$ Underreporting leads to underestimation of the relative risks for increased sickness absence and disability pensioning for high consumers/ problem drinkers.

Another plausible cause of systematic error is non-participation. Earlier reports from Sweden show that alcohol problems, as stated in social registers and/or from hospital records, are more common among non-respondents than among respondents. ${ }^{30-32}$ One report based on the HPS study found a higher percentage of inpatients with alcohol related diseases among the non-participants. ${ }^{29}$ In the same way, high consumers with alcohol related consequences in the form of high sickness absence and disability pensioning probably are represented among non-responders to a greater extent, diluting the relative risks. In a study on middle aged men, alcohol dependence was a more common cause for disability pensioning among non-participants in a screening programme. ${ }^{17}$

The dependent variable, namely, information from the National Swedish Social Insurance Board on sick leave and disability pensioning, can be regarded as reliable. Indirectly, however, there might be a systematic error as people with no or very few registered sick days may include people who are in fact not present in the labour market, even though they qualify for sickness benefits (such as students and parents on parental leave). This kind of misclassification of sick leave in which people are in fact sick but are not listed as being on sick leave is probably the same for abstainers, moderate drinkers, and high consumers and therefore will not influence the relative risk figures. People who can be off from work without being listed on sick leave (private entrepreneurs and high level employees) will cause another kind of misclassification. This problem probably affects all studies on sick leave because higher socioeconomic groups and entrepreneurs have more opportunities to control their own work and to be off work without registering. In addition, this type of misclassification is only a problem if you want to study the effect of hazardous drinking on absence from work, irrespective of whether the incapacity is compensated with sick allowance. Thus, being listed as sick is not a perfect measure of absence from work because of sickness. However, as our focus has been on very high sickness absence, the effect of this problem ought to be minimised because the possibility of being off work without being listed as sick for other than short periods would be very small.

PRACTICAL IMPLICATIONS

The study shows that at a group level, alcohol habits have a great effect on sickness absence. A natural preventive consequence, aside from preventive efforts to reduce the alcohol intake of the general population, is to consider alcohol habits in all health examinations, as well as among patients in the primary health care and
KEY POINTS

- Self reported high alcohol consumption in a health survey is a predictor of a subsequent increase in days of sick leave and of disability pensioning among both men and women.

- In all health examinations, as well as among patients in the primary health care and occupational health services, preventive efforts should be targeted against alcohol habits.

- Rehabilitation efforts among people with high sickness absence should take their alcohol habits into consideration.

occupational health services. In this way, hazardous drinking habits could be identified at an early stage in many more subjects than is done today. Primarily, preventive efforts could be established through small and relatively low cost interventions. A review of brief interventions for alcohol problems made by Bien et al indicates that such interventions are more effective than no counselling at all and that the course of harmful alcohol use can be effectively altered through relatively brief contacts. ${ }^{33}$ In Sweden, Kristenson's study in Malmö has shown that small efforts among middle aged men could give very good results with respect to sickness absence, hospitalisation, and mortality. ${ }^{34}$

However, a change in attitudes is necessary to change the course of harmful alcohol use on a broad scale. By pretending that the problem does not exist, supervisors in both the medical care and social welfare systems display the attitude that hazardous drinking is so worthy of blame that we cannot even talk about it. Without a strong wish, combined with empathy, to identify high consumers among the general population or in a certain context, professionals in both the medical care and social welfare systems will continue to pay attention to the consequences of hazardous drinking habits rather than to alcohol habits in themselves. If, on the other hand, hazardous alcohol consumption is considered at an early stage, appropriate treatment and rehabilitation measures will be performed at an earlier stage, increasing the chances of recovering and avoiding lifelong exclusion from working life. We thank Anders Leifman for skilful computer programming
and for statistical support. Funding: financial support was and for statistical support. Funding: financial support was
received from the Swedish Council for Social Research (project received from the
no $93-145: 2 B)$.

1 Alexandersson K. Sickness absence in a Swedish county with reference to gender, occupation, pregnancy and parenthood. [MD thesis]. Linköping: Linköping University, no 734,1995 .

2 Isacsson A, Hansson BS, Janzon L, et al. The epidemiology of sick leave in an urban population in Malmö, Sweden. Scand F Soc Med 1992;20:234-9.

3 Åstrand NE, Isacsson SO, Olhagen GO. Prediction of early retirement on the basis of a health examination. Scand $\mathcal{F}$ Work Environ Health 1988;14:110-17.

4 Blank N, Diderichsen F. Short-term and long-term sick leave in Sweden: relationships with social circumstances, working conditions and gender. Scand f Soc Med, 1995;4:265-72.

5 Alexandersson K, Leijon M, Åkerlind I, et al. Epidemiology of sickness absence in a Swedish county in 1985, 1986 and 1987. Scand F Soc Med 1994;1:27-34. 
6 Edén L, Ejlertsson G, Lamberger B, et al. Immigration and socio-economy as predictors of early retirement pensions. Scand 7 Soc Med 1994;3:187-93.

7 North F, Syme SL, Feeney A, et al. Explaining socioeconomic differences in sickness absence: the Whitehall II study. BMF 1993;306:361-6

8 Stansfeld S, Feeney A, Head J, et al. Sickness absence for psychiatric illness: the Whitehall II study. Soc Sci Med 1995;2:189-97.

9 Marmot M, Feeney A, Shipley M, et al. Sickness absence as a measure of health status and functioning: from the UK Whitehall II study. $\mathcal{F}$ Epidemiol Community Health 1995;49: 124-30.

10 Spak F, Hensing G, Allebeck P. Sick leave in women with alcohol dependence or abuse. Effects of additional psychiatric disorders. Soc Psychiatry Psychiatr Epidemiol 1998;33. 613-19.

11 Hensing G, Spak F. Psychiatric disorders as a factor in sick leave due to other diagnoses. A general population-based leave due to other diagnoses. A gener.
study. Br f Psychiatry 1998;172:250-6.

12 Jenkins R. Sex differences in alcohol consumption and its associated morbidity in young civil servants. $B r \mathcal{F}$ Addict associated morbidit

13 Jenkins R, Harvey S, Butler T, et al. A six-year longitudinal study of the occupational consequences of drinking ove "safe limits" of alcohol. Br F Ind Med 1992;49:369-74.

14 Marmot MG, North F, Feeney A, et al. Alcohol consumption and sickness absence: from the Whitehall II study. Addiction 1993;88:369-82.

15 Kristenson H, Öhrn J, Hood B. Convictions for drunkenness or drunken driving, sick-absenteeism, and morbidity in middle-aged males with different levels of serumgamma-glutamyltransferase. Prev Med 1982;11:403-16.

16 Medhus A. Alcohol problems among male disability pensioners. Scand $\mathcal{F}$ Soc Med 1976;4:159-62.

17 Månsson N-O, Råstam L, Eriksson K-F, et al. Incidence of and reasons for disability pension in a Swedish cohort of middle-aged men. Eur f Public Health 1994;4:22-6.

18 Månsson N-O, Israelsson B. Middle-aged men before and after disability pension. Scand $\mathcal{F}$ Soc Med 1987;15:185-9.

19 Månsson N-O, Råstam L, Eriksson K-F, et al. Alcohol consumption and disability pension among middle-aged men. In: Månsson N-O. Disability pension. Epidemiological and financial aspects. [MD thesis]. Lund: University of Lund, 1997.
20 Upmark M, Hemmingsson T, Romelsjö A, et al. Predictor of disability pension among young men. The role of alcohol of disability pension among young fuctic Health 1997;1:20-8.

21 Diderichsen F, Halldin J, Holland S, et al. The health of the population in Stockholm County. Green Report 270. Sundbyberg: Depa

22 The Royal College of Psychiatrists. Alcohol: our favourite drug. London: Tavistock, 1986.

23 Health Educational Council. That's the limit: a guide to sensible drinking. London: HEC Publications, 1983.

24 Mayfield D, McLeod G, Hall P. The CAGE questionnaire: validation of a new alcoholism screening instrument. $A m \mathcal{F}$ Psych 1974;131:1121-3.

25 Leifman $\mathrm{H}$, Kühlhorn E, Allebeck $\mathrm{P}$, et al. Abstinence in late adolescence. Antecedents to and covariates of a sober lifestyle and its consequences. Soc Sci Med 1995;1:113-21.

26 Pell S, D'Alonzo CA. Sickness absenteeism of alcoholics. $\mathcal{F}$ Occup Med 1970;12:198-210.

27 National Insurance Board Statistics of the Social Insurance. Facts 1992. Stockholm: National Insurance Board, 1994. [In Swedish]

28 Statistical Yearbook of Sweden 93. Stockholm: Statistics Sweden, 1993

29 Romelsjö A, Boström G, Leifman H, et al. Comparison of various measures of alcohol problems in a general population survey in Stockholm. KI Green Report 270. Sundbyberg: Department of Social Medicine, Karolinska Institute, 1992.

30 Tibblin G. A population study of 50 -year-old men. An analysis of the non-participation group. Acta Med Scand 1965;178:453-9.

31 Wilhelmsen L, Ljungberg S, Wedel $\mathrm{H}$, et al. A comparison between participants and non-participants in a primary preventive trial. $\mathcal{F}$ Chron Dis 1976;29:331-9.

32 Persson J, Magnusson PH. Sickness absenteeism and mortality in patients with excessive drinking in somatic mortality in patients with excessive drinking in somatic

33 Bien TH, Miller WR, Tonigan IS. Brief interventions for alcohol problems: a review. Addiction 1993;88:315-36.

34 Kristenson $\mathrm{H}$, Öhlin $\mathrm{H}$, Hultén-Nosslin MB, et al. Identification and intervention of heavy drinking in middle-aged men: results and follow-up of 24-60 months of long-term study with randomized controls. Alcohol Clin Exp Res 1983; 2:203-9. 